\title{
Impact of Strategic Planning on Organizational Performance of Health Care Services in Nigeria
}

\author{
Aderibigbe Elkanah Oludele \\ Department of Business Administration, Faculty of Management Sciences, Nile University of Nigeria, Abuja, Nigeria \\ Email address: \\ oluaderibigbe1@yahoo.com \\ To cite this article: \\ Aderibigbe Elkanah Oludele. Impact of Strategic Planning on Organizational Performance of Health Care Services in Nigeria. Science \\ Journal of Business and Management. Vol. 9, No. 3, 2021, pp. 209-214. doi: 10.11648/j.sjbm.20210903.18
}

Received: June 24, 2021; Accepted: July 13, 2021; Published: August 2, 2021

\begin{abstract}
Strategic planning is a concept that has posed so many problems to several organizations in its applicability. However, for any organization to thrive well in this modern contemporary age there is need for such organization to embrace strategic planning in its fullness. This objective of the study aims at examining the influence of strategic processes on organizational development and growth of the public health institution in Nigeria. The strategic plan outlines a plan or strategy to improve the organizational performance, effectiveness as well as overall efficiency of an institution whether public or private. Typically, as an approach to strategy formulation, strategic planning includes elements such as analysis of the organization's mandate, mission, and values, analysis of the organization's internal and external environment and the formulation of strategic issues based on these analyses and the formulation of strategies, goals, and plans to address the issues. Numerous research studies show that many institutions are often involved in strategic planning in order to attain and maintain the organizational goals of profit maximization and greater market share. Also these studies in literature show that the development and implementation of it has a direct influence on the efficiency and effectiveness of health institutions with increases in the performance of departments and longevity of the institution. Therefore, the study seeks to investigate the ability of strategic planning to provide similar results as in quality service delivery of the health sector in Nigeria, which is known for inefficiency and underdevelopment. Therefore, this research focuses on examining the systems, types and implications of the strategic approach for institutional performance in the public health sector.
\end{abstract}

Keywords: Strategic Planning, Performance, Health Sector, Public Sector, Nigeria

\section{Introduction}

The ability to plan strategically has been very crucial task that goes hand in hand with the design and structure of any working system by many companies over the years. It is a process of developing methods and structures to help run an organization $[2,14,20]$. There still exist arguments about its usefulness and the importance of strategic planning to the business environment [2]. This critique of the strategic planning concepts is inconsistent, lacks consensus and differs in its design, construction, and implementation in various systems (Bryson, Crosby, \& Stone, 2015). However, some scholars describe it as an adaptive tool for its adoption and use, taking into account the organization, and therefore argue that it is useful for creating flexibility in changing situations. The designing of a strategic plan involves a thorough participation by all units, implementation of strategic plans, and the enforcement of strategic plans $[11,14]$.

In general, the literature suggests that the plan should be structured according to the needs of the sectors, and suggests that the effectiveness of planning strategically should be consistent with the organizational style. Therefore, it is clear that institutions need to develop guidelines to serve as a direction for their units to increase the chances of achieving their goals. In the case of Nigeria, sparse research has been carried out on the organizational performance of public health institutions because of strategic planning.

Research Objectives

Therefore, the main objective of the study is to examine the impact of strategic planning on the organizational performance of public health institutions in Nigeria. This leads the study to answer the research objectives:

1. What is the impact of strategic planning on public health institutional performance? 
2. Determine the effect of strategic planning on organization performance.

3. Determine whether poor performance of strategic planning has significant effect on organizational performance.

The research question will help analyze the research gap in literature which involves the lack of investigation into strategic planning in the public health institution. This will lead to the examination of Nigeria's public sector structuring and operational processes, examining the planning process used by government agencies and government departments. The research objectives include:

1. To investigate the impact of strategic planning on organizational performance.

2. To examine the determinants of organizational performance factors such as management, economic and environmental factors.

3. To examine the relationship between strategic planning and organizational performance.

The research objectives give room to examine three research hypotheses:

$H_{1}$ : Strategic planning has a positive impact on institutional performance.

$\mathrm{H}_{2}$ : It is a determinant of factors such as management, economic and environmental factors.

$\mathrm{H}_{3}$ : Positive relationship between strategic planning and organizational performance.

\section{Literature Review}

The review of literature with particular reference to organizational systems and planning processes has over the years, shown the usefulness of development plans and organizational strategies for financial management and sustainable organizational growth [5]. In 1920, Harvard University created a strategic planning system for its organization, which allowed them to "fit in" nicely between the business community and its surroundings. The military has been involved in the strategic planning since the beginning of the Roman conquest, using new military methods in the American Civil War in 1860 [14].

Despite the differences between the private sector and the public sector, especially in terms of profit, each sector is pushing strongly in the hope that it can achieve higher standards in the fulfillment of its mission [1]. Many scholars believe that plans should be simple, promising, and not overly exaggerated $[8,12]$. In today's world, many leaders spend a lot of time, energy, and money building basic policies and devoting themselves to planning for the sustainable growth of their institutions. However, the literature has shown that the biggest problems with the implementation of strategic plans in a system are the commitment of the staff that will carry out the plans [6]. This means that a number of studies see employee engagement as a mitigating factor implying that there is a need for management to inculcate its employees in the structuring of plans for organizational development [18].

\subsection{Strategic Planning for Public Sector}

Government officials use this process, due to major changes that occur in public sector, and has force them analyze more deeply about public sector needs [2]. Strategic plans should involve community workers, employees and other stakeholders in an organization [5], suggests that it is important and can be a natural part of the policy of public enterprises. However, developing a strategic planning framework with other parastatals and government agencies can be difficult and public purpose. In the management of public service, the organizational planning structure should focuses on the overall improvement of the organization and its activities.

Based on the research by [2], there are three factors associated with structuring a strategic plan for any public sector institution: purpose, budget, organizational objectives. The study shows that different organizations have their own needs, with each department having a unique planning structure that will guide them, rather than a rigid plan used by all agencies and institutions in the public sector which is a major challenge in the Nigerian public sector. According to $[15,18]$, public services often have rules and restrictions that may explain the purpose and extent of their strategic planning ability. The main driving force is not profit but activities around the planning of budgets meaning the elements of competition that makes an intense need to grow is missing.

Another important area in literature is the role of people in strategic and process design. Previous studies recognize that people are an integral part of the process and are essential for the success of strategic planning [4, 11, 13, 19, 20]. Poister and Streib, (2018), points out that it is very not easy to identify the things that make up an effective public institution, but he identifies four strategic functions that he considers vital for the success of strategic planning: leadership, team, skills, and external input. The importance of people in design methods stems from the fact that three of the four important tasks confront people with their role in strategic planning design.

Although the public sector strategic planning has well known with the public, there is debate over whether private sector development plans can be applied in the public sector. Bloom (2014) describes this as written: "While no one opposes the use of strategic planning, some argue that the distinction between the public and private sectors is important for all approaches. There are a wide range of ways to manage the public sector. "[4]. These differences include the public sector policy environment, involvement of external factors, difficulties in implementing plans, and lack of independent institutions [4].

\subsection{The Effectiveness of Strategic Planning in Public Health Institutions}

Assessing the efficiency of the strategic model in government ministries and agencies is a difficult task (Ramakrishna, 2019). The nature of the environment around government agencies makes it difficult to determine the value of financial performance or physical labor in planning efforts [3]. It is difficult to articulate the influence of strategic planning on the 
impact of other factors such as governance, population change, and changes in state and federal finances, politics, organizational competition, social power and culture $[1,2]$. This complex challenge is the main reason for the lack of studies that measure the impact of strategic planning on government. Birnbaum (2013) found little experimental evidence to assess the effectiveness of the control systems. His study analyzed the data from public institutions after evaluating large data on a number of public institutions and the level of inadequate data in the system was a hindrance to an effective analysis.

This means that information is not slow in government or in the public sector; however, there is not enough evidence to support the government's statements and decisions [9]. Health, the conclusions about the effective health plans of public institutions are based solely on the evaluation of the general public sector. Doris (2014) stated that the development of a strategic plan is in line with the institution's objectives to reflect the prudent development and importance of strategic planning in the Nigerian public organization. Strategic planning is concerned with coordinating long-term planning through the development and planning of economic and environmental awareness and the planning of vision, goals, and objectives [8]. According to a number of authors, the study identified a number of guidelines that showed the implementation of strategic plans in the public sector $[8,20]$. These include; the provision of long-term guidance for ongoing regime; Better organization and communication; formulation of priorities and focus on securing resources in key areas. The Increase of remuneration among the institution's stakeholders and make them part of the organization. This will end up expanding the strategic planning function in the organization $[10,15]$.

However, there is still no consensus on the results of studies on the subject [18]. For example, [14] found that strategic planning had a positive effect on the performance of a controlled environment in an uncertain and rigid environment as well as no effect on a controlled environment. In addition, several authors have found that strategic planning has a positive effect on performance [14]. Shrader, 2018 did not have a positive relationship in his study. In addition, studies on the relationship between strategy planning and staff performance where found to have positive results [16]. The study goes on to analyze the relationship and impact of strategic planning and performance to provide important information about the development of public health sector in Nigeria. These results will be beneficial to government officials, partners and organizations in making the strategic planning more effective.

\section{Methodology}

The coverage of this research method is descriptive but also involves quantitative research involving the use of a number of health institutions. Questionnaires were adopted to collect primary data relevant in answering the study's research questions. Twenty questions of strongly agreed to and strongly disagreed on a five Likert scale was utilized in the questionnaire. Fifty (50) employees were asked questions in the Federal medical service center Abuja, which was the case study institution, including adults and youth of the center. Thirty (30) employees were able to complete and return the questionnaires. These responses were augmented by interview questions provided by the institution's planning manager and other department heads.

In other words, this type of quota will be limited to 40 employees in the departmental organization as well as in other departments. A randomized controlled trial was used to develop the research materials for this study.

\section{Stage 1}

$\mathbf{H}_{1}$ : Strategic planning has a positive impact on organizational performance

\begin{tabular}{llcccc}
\hline & & Frecuency & $(\%)$ & Valud (\%) & Cumulative (\%) \\
\hline Valid & Strongly area & 56 & 70.0 & 70.0 & 70.0 \\
& Agree & 18 & 22.5 & 22.5 & 92.5 \\
& Undecided & 6 & 7.5 & 7.5 & 100.0 \\
& Total & 80 & 100.0 & 100.0 & \\
\hline
\end{tabular}

Stage 2 .

\section{T-Test}

\begin{tabular}{llll}
\hline $\mathrm{N}$ & Mean & SD & SEM \\
\hline 80 & 4.63 & 0.62 & $6.98 \mathrm{E}-02$ \\
\hline
\end{tabular}

\section{Stage 3}

\begin{tabular}{|c|c|c|c|c|c|}
\hline \multicolumn{6}{|c|}{ Test value $=0.05$} \\
\hline \multirow[b]{2}{*}{$t$} & \multirow[b]{2}{*}{ df } & \multirow[b]{2}{*}{ Sig (2-tailed) } & \multirow[b]{2}{*}{ Mean difference } & \multicolumn{2}{|c|}{$(95 \%)$ confidence interval of the difference } \\
\hline & & & & Lower & Upper \\
\hline 65.588 & 79 & 0.000 & 4.58 & 4.44 & 4.17 \\
\hline
\end{tabular}

Figure 1. Outcome of T-test for hypothesis 1. 


\section{Findings}

To test the above hypothesis, the study makes use of the Ttest statistical technique also known as the parametric test method of analysis. It also utilizes the Chi-square which is a non-parametric testing method. The research question which is stated: What is the impact of strategic planning on public health institutional performance? Will be examined using the following hypothesis:

$H_{1}$ : Strategic planning has a positive impact on institutional performance.

$\mathrm{H}_{2}$ : It is a determinant of factors such as management, economic and environmental factors.

$H_{3}$ : Positive relationship between strategic planning and organizational performance.
Hypothesis I: Strategic planning has a positive impact on institutional performance.

\section{Interpretation}

Given that the analysis is a 2-tailed test with a degree of freedom of 80.1 , the $t$ value from the result was 65.6. which turned out to be greater than the computed value of 2 . This means that from the result we have to reject the null hypothesis which says there is no impact or there is a negative impact of strategic planning on organizational performance and accept the alternative hypothesis which implies that strategic planning has a positive impact on organizational performance of the public health institution under survey.

Hypothesis II: It is a determinant of factors such as management, economic and environmental factors.

Stage 1

\begin{tabular}{llcccc}
\hline & & Frequency & $(\%)$ & Valud (\%) & Cumulative (\%) \\
\hline Valid & Strongly area & 44 & 55.0 & 55.0 & 55.0 \\
& Agree & 27 & 33.8 & 33.8 & 88.8 \\
& Undecided & 9 & 11.3 & 11.3 & 100.0 \\
& Total & 80 & 100.0 & 100.0 & \\
\hline
\end{tabular}

Stage 2

\begin{tabular}{lccccc}
\hline & Observed $(0)$ & Expected $(\mathrm{E})$ & Residual $(0-\mathrm{E})$ & $(0-\mathrm{E})^{2}$ & $(0-\mathrm{E})^{2} / \mathrm{E}$ \\
\hline Undecided & 9 & 26.7 & -17.7 & 313.29 & 11.7 .00 \\
Agree & 27 & 26.7 & 0.3 & 0.09 & 0.0034 \\
Strongly agree & 44 & 26.7 & 17.3 & 299.30 & 11.2 .00 \\
Total & 80 & 80.0 & & & 22.9 .00 \\
\hline
\end{tabular}

\section{Stage 3}

\begin{tabular}{lr}
\hline Chi-square df & 22.975 \\
df & 2.000 \\
Asymp. sig & 0.000 \\
\hline
\end{tabular}

Figure 2. Outcome of Chi-square for hypothesis II.

Stage 1

\begin{tabular}{|c|c|c|c|c|c|}
\hline & & Frequency & $(\%)$ & Valud $(\%)$ & Cumulative (\%) \\
\hline \multirow[t]{4}{*}{ Valid } & Strongly area & 39 & 48.8 & 48.8 & 48.8 \\
\hline & Agree & 38 & 47.5 & 47.5 & 96.3 \\
\hline & Undecided & 3 & 3.8 & 3.8 & 100.0 \\
\hline & Total & 80 & 100.0 & 100.0 & \\
\hline
\end{tabular}

Stage 2

\begin{tabular}{|llll|}
\hline T-Test & & & \\
\hline $\mathrm{N}$ & Mean & SD & SEM \\
\hline 80 & 4.45 & 0.57 & $6.39 E-02$ \\
\hline
\end{tabular}

\section{Stage 3}

\begin{tabular}{|c|c|c|c|c|c|}
\hline \multicolumn{6}{|c|}{ T-Test } \\
\hline \multicolumn{6}{|c|}{ Test value $=0.05$} \\
\hline \multirow[b]{2}{*}{$t$} & \multirow[b]{2}{*}{ df } & \multirow[b]{2}{*}{ Sig. (2-tailed) } & \multirow[b]{2}{*}{ Mean difference } & \multicolumn{2}{|c|}{$(95 \%)$ confidence interval of the difference } \\
\hline & & & & Lower & Upper \\
\hline 68.865 & 79 & 0.000 & 4.40 & 4.27 & 4.53 \\
\hline
\end{tabular}

Figure 3. Outcome of T-test for Hypothesis III. 


\section{Interpretation}

Given a computed value of 6 which was an approximated value from 5.999, with a df of 2 . The calculated value was higher which at a level of 22.9. This implies that we accept the alternative hypothesis and reject the null hypothesis. This implies that Strategic planning is determined by managerial, environmental and organizational factors.

Hypothesis III: Positive relationship between strategic planning and organizational performance.

\section{Interpretation}

Given that the analysis is a 2-tailed test with a degree of freedom of 80.1, the $\mathrm{t}$ value from the result was 79 which turned out to be greater than the computed value of 1.99. This means that from the result we have to reject the null hypothesis which says there is no link or there is a negative link between strategic planning on organizational performance and accept the alternative hypothesis which implies that strategic planning has a positive impact on organizational performance of the public health institution under survey, we reject the null hypothesis (Ho) and accept the alternative hypothesis (Hi). This implies that there is a link between strategic planning and organization's performance.

\section{Conclusion}

In the results of several studies, the results show an important fact that gave a clear result to the research. Given the high percentage and support for these three experimental methods, conclusions can be drawn with $95 \%$ confidence that strategic planning can improve efficiency and survival of federal medical service centre which is a sample for other health institutions in Nigeria.

Most respondents agreed that it improves work planning and is part of the concept used in the study. Almost all respondents responded and agreed that there is a relationship between organizational structure and organizational growth, which was the final conclusion examined in the study, Nevertheless, none of the protesters rejected the hypothesis. Also, the study revealed that strategic planning is a dynamic process of formulation, implementation, evaluation and control of strategies to realize the organization's strategic intent. Therefore, it can be concluded that there is a relationship between organizational planning and organizational performance.

\section{References}

[1] Abubakar, U. I., Hassan, I. (2017). Theoretical perspectives of management and their application in AbubakarRimi Television, Kano State, Nigeria. IOSR Journal of Humanities and Social Science, 22 (11): 18-28. doi: 10.9790/08372211081828.

[2] Arend, R. J., Zhao, Y. L., Song, M., \&Im, S. (2019). Strategic planning as a complex and enabling managerial tool. Strategic Management Journal, 38 (8), 1741-1752. doi: 10.1002/smj.2420.
[3] Birnbaum, L. S. (2013). NIEHS's new strategic plan. Retrieved from: https://ehp.niehs.nih.gov/doi/full/10.1289/ehp.1205642

[4] Bloom, M. J., \&Menefee, M. K. (2014). Scenario planning and contingency planning. Public Productivity \& Management Review, 17 (3), 223-230. doi: 10.2307/3380654.

[5] Bryson, J. M., Crosby, B. C., \& Stone, M. M. (2015). Designing and implementing cross-sector collaborations: Needed and challenging. Public administration review, 75 (5), 647-663. doi: 10.1111/puar.12432.

[6] Debarliev, S., \&Suklev, B. (2018). Strategic planning effectiveness comparative analysis of the Macedonian context. Economic and Business Review, 14 (1), 63-93.

[7] Ebanna, S., Child, J., \& Dayan, M. (2013). A model of antecedents and consequences of intuition in strategic decision-making: Evidence from Egypt. Long Range Planning, 46 (1-2), 149-176. doi: 10.1016/j.lrp.2012.09.007.

[8] Ghobadian, A., O'regan, N., Thomas, H., \& Liu, J. (2018). Formal strategic planning, operating environment, size, sector and performance: Evidence from the UK's manufacturing SMEs. Journal of General Management, 34 (2), 1-20. doi: 10.1177/030630700803400201.

[9] Griggs, H. E. (2020). Strategic planning system characteristics and organizational effectiveness in Australian small-scale firms. Irish Journal of Management, 23 (1), 23-51.

[10] Jimenez, B. S. (2016). Strategic planning and the fiscal performance of city governments during the Great Recession. The American Review of Public Administration, 43 (5), 581601. doi: $10.1177 / 0275074012451051$.

[11] Kemp J, E. J., Funk, R. J., \&Eadie, D. C. (2013). Change in chewable bites: Applying strategic management at EEOC. Public Administration Review, 53 (2), 129-134. doi: $10.2307 / 976705$.

[12] Murphy L. B. (2015). Strategic planning and firm performance: A synthesis of more than two decades of research. Academy of Management Journal, 37 (6), 16491665. doi: $10.5465 / 256804$.

[13] Poister, T. H. (2018). The future of strategic planning in the public sector: Linking strategic management and performance. Public Administration Review, 70 (1), 246-254. doi: 10.1111/j.1540-6210.2010.02284.x.

[14] Priem, R. L., Rasheed, A. M., \&Kotulic, A. G. (2016). Rationality in strategic decision processes, environmental dynamism and firm performance. Journal of Management, 21 (5), 913-929. doi: 10.1177/014920639502100506.

[15] Schwarz, J. O. (2019). Business war gaming: developing foresight within a strategic simulation. Technology Analysis \& Strategic Management, 21 (3), 291-305. doi: $10.1080 / 09537320902750590$.

[16] Schwenk, C. R., \&Shrader, C. B. (2018). Effects of formal strategic planning on financial performance in small firms: A meta-analysis. Entrepreneurship Theory and Practice, 17 (3), 53-64. doi: 10.1177/104225879301700304.

[17] Spee, A. P., \&Jarzabkowski, P. (2020). Strategic planning as communicative process. Organization Studies, 32 (9), 12171245. doi: 10.1177/0170840611411387. 
[18] Tapinos, E., Dyson, R., \& Meadows, M., (2019). The impact of performance measurement in strategic planning. International Journal of Productivity and Performance Management, $54 \quad(5 / 6), \quad 370-384 . \quad$ doi: 10.1108/17410400510604539/full/html.

[19] Vinzant, J. C., \&Vinzant, D. H. (2019). Strategic management spin-offs of the Deming approach. Journal of Management
History, $5 \quad$ (8), 516-531. doi: 10.1108/13552529910290629/full/html.

[20] Wandjiva, J. T. (2019). An exploratory study on strategic planning and the role of communication in the public service of Namibia with specific reference to the Ministry of Gender Equality and Child Welfare (Doctoral dissertation). Namibia University of Science and Technology, Namibia. 